\title{
Fate of fructo-oligosaccharides in the human intestine
}

\author{
BY MARTINE S. ALLES ${ }^{1}$, JOSEPH G. A. J. HAUTVAST ${ }^{1}$, \\ FOKKO M. NAGENGAST ${ }^{2}$, RALF HARTEMINK ${ }^{3}$, KATRIEN M. J. VAN LAERE ${ }^{3}$ \\ AND JAN B. M. J. JANSEN ${ }^{2}$ \\ ${ }^{1}$ Department of Human Nutrition, Wageningen Agricultural University, The Netherlands \\ ${ }^{2}$ Department of Gastroenterology and Hepatology, University Hospital St Radboud, Nijmegen, \\ The Netherlands \\ ${ }^{3}$ Department of Food Science, Wageningen Agricultural University, The Netherlands
}

(Received 10 July 1995 - Revised 6 November 1995 - Accepted 5 December 1995)

\begin{abstract}
There is a need for studies on colonic fermentation in order to learn more about health and diseases of the colon. The aim of the present study was to evaluate the fate of two different doses of fructooligosaccharides $(5$ and $15 \mathrm{~g} / \mathrm{d}) \mathrm{v}$. glucose in the intestine of healthy men. Twenty-four volunteers participated in a 5-week study. The study was a completely balanced multiple crossover trial using an orthogonal Latin-square design for three periods, with supplement periods of $7 \mathrm{~d}$ and two $7 \mathrm{~d}$ wash-out periods. Breath samples and faecal samples were collected. There was a clear gaseous response to the consumption of fructo-oligosaccharides. The highest dose significantly increased $24 \mathrm{~h}$ integrated excretion of breath $\mathrm{H}_{2}(P<0.05)$. Breath $\mathrm{H}_{2}$ excretion after ingestion of $5 \mathrm{~g}$ fructo-oligosaccharides was higher than control, but did not reach significance. No effects on the total concentration of short-chain fatty acids in faeces were observed, no modification of the molar proportions of the various short-chain fatty acids was observed. The faecal pH did not change. No changes in faecal weight were observed. No fructo-oligosaccharides were recovered in faeces. We conclude that fructo-oligosaccharides added to the diet of young Western subjects are fully metabolized in the large intestine. The level of fermentation seems to be dose-dependent.
\end{abstract}

Fructo-oligosaccharides: Colon: Short-chain fatty acids: Breath hydrogen

Studies on the effects of non-digestible oligosaccharides in elderly Japanese subjects suggest that dietary supplementation with fructo- or galacto-oligosaccharides is beneficial to the large intestine (Hidaka et al. 1986; Masai et al. 1987; Mitsuoka et al. 1987; Hayakawa et al. 1990; Ito et al. 1990). The studies show a higher activity of the colonic microflora in response to the consumption of oligosaccharides, as demonstrated by increased fermentation. During carbohydrate fermentation, gases and short-chain fatty acids are formed (Cummings et al. 1987; Wang \& Gibson, 1993). The production of short-chain fatty acids and the subsequent drop in colonic $\mathrm{pH}$ might protect against colonic cancer (Koo \& Rao, 1991; van Munster et al. 1994). It is also suggested that oligosaccharides selectively stimulate bifidobacterial growth and thereby change the microfloral composition. Since bifidobacteria are considered to be beneficial genera, they may contribute to the establishment of a more healthy colonic environment (Mitsuoka, 1990; Modler et al. 1990; Gibson et al. 1995).

However, because the Japanese studies often lacked a strict study design or focused primarily on elderly people, we feel that they do not elucidate the metabolic fate of oligosaccharides in the large intestine. Also, observations made in Japan might not be applicable to populations with Western dietary patterns. Only a few studies have been 
performed within Western populations so far and they have not investigated to what degree the oligosaccharides are fermentable (Stone-Dorshow \& Levitt, 1987; Rumessen et al. 1990 ; Gibson et al. 1995). Thus, we need more information to evaluate the fermentation process of oligosaccharides.

The purpose of the present study was to examine the fate of fructo-oligosaccharides in the human intestine by studying several aspects of colonic fermentation in healthy young adults consuming a Western diet. The excretions of unfermented fructo-oligosaccharides and short-chain fatty acids in the faeces, and $\mathrm{H}_{2}$ in the breath were measured.

\section{METHODS}

Subjects and experimental design

Twenty-four healthy men aged 19-28 years volunteered to participate in the study. Women were excluded because of the possible influence of the menstrual cycle on fermentation (McBurney, 1991). All subjects had normal body weight (BMI 21.7 (SD 1.9) kg/m²), had no history of diabetes or gastrointestinal disease, and had not recently been treated with antibiotics or laxatives. They were not under any medication and blood screening tests were normal. None of the volunteers smoked. Four volunteers were vegetarians, none of the volunteers used a special diet.

To avoid excess $\mathrm{H}$ being channelled into $\mathrm{CH}_{4}$ production, subjects chosen were non- $\mathrm{CH}_{4}$ producers. Three breath samples were collected on separate days, from each volunteer, before the study. Volunteers were classified as $\mathrm{CH}_{4}$ excreters, when in one or more of the samples the $\mathrm{CH}_{4}$ concentration exceeded 3 ppm above ambient air (Nagengast et al. 1988; Rumessen, 1992). Characteristics of the study population are given in Table 1.

The study was a completely balanced multiple crossover trial using an orthogonal Latinsquare design for three treatments, with supplement periods of $7 \mathrm{~d}$ and two $7 \mathrm{~d}$ wash-out periods between treatments. The volunteers consumed three different supplements in random order. At the end of the each supplement period faeces, breath and urine samples were collected. All subjects gave their informed written consent before participating. The study protocol was approved by the Ethical Committee of the Department of Human Nutrition, Wageningen Agricultural University.

\section{Supplements and food intake}

Diet composition was calculated in every supplement period from $2 \mathrm{~d}$ estimated records, using the 1986 release of The Netherlands nutrient data bank (Stichting Nederlands Voedingsstoffenbestand, 1986). Volunteers were asked to refrain from eating any fermented dairy products during the study.

The supplements consisted of fructo-oligosaccharides (Raftilose P95; ORAFTI, Tienen, Belgium) and/or glucose (Cerestar Pur 01934; Cerestar Benelux BV, Sas van Gent, The Netherlands) in the following quantities: control, $0 \mathrm{~g}$ fructo-oligosaccharide $+4.1 \mathrm{~g}$ glucose; SF5, $5 \mathrm{~g}$ fructo-oligosaccharides $+2.7 \mathrm{~g}$ glucose; SF15, $15 \mathrm{~g}$ fructo-oligosaccharides $+0 \mathrm{~g}$ glucose. They were dissolved in water and were of equal osmolarity. Supplements were consumed in split dose together with breakfast and dinner. To estimate stool recovery, thirty Ba-impregnated rings were swallowed daily together with the supplements and were counted afterwards in the faecal samples.

A small dose $(240 \mu \mathrm{mol})$ of $\mathrm{LiCl}$ (Merck, Darmstadt, Germany) was added to each supplement. To check for compliance, the recovery of $\mathrm{Li}$ in $24 \mathrm{~h}$ urine was measured on the last $2 \mathrm{~d}$ of every supplement period (Sanchez-Castillo et al. 1987; van Houwelingen et al. 1987; Leclercq et al. 1990). 
Table 1. Characteristics and dietary intake of the subjects

(Mean values and standard deviations for twenty-four male subjects)

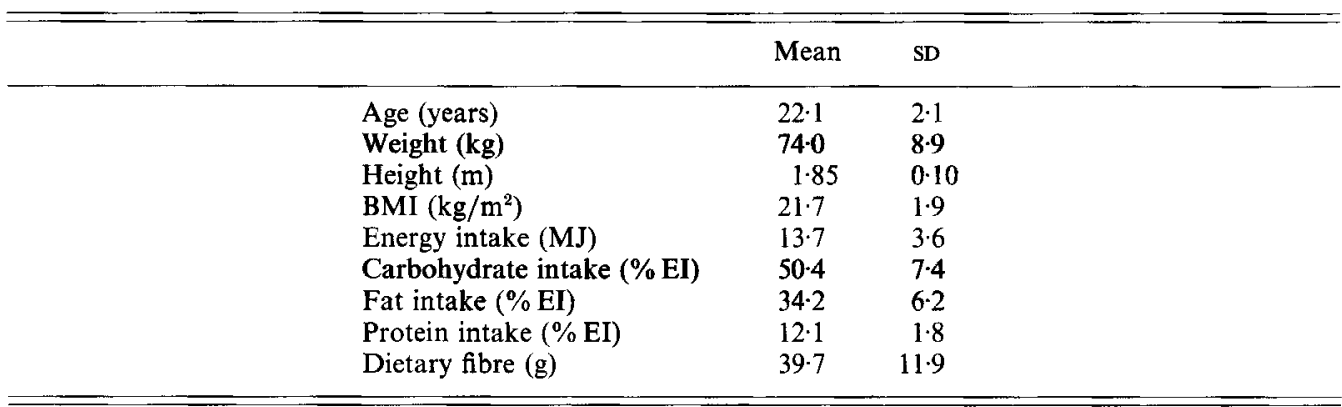

EI, energy intake.

\section{Data collection}

Body weight was measured on the first day of every supplement week, using electronic scales with a digital read-out to an accuracy of $0.05 \mathrm{~kg}$ (ED60-T; Berkel, Rotterdam, The Netherlands).

During the whole study period, volunteers kept a diary. They recorded time of supplement consumption, time of defaecation, possible diseases or medication and deviations in eating, drinking or living behaviour. Stool form was rated for all stools on a 5-point Likert scale which was based on the scale by Heaton et al. (1992) (watery; soft, pudding-like; soft, snake-like; dry, cylindric; dry, hard pellets). Gastrointestinal complaints concerning flatulence, bloating, abdominal pains or cramps, eructations, nausea, vomiting and stomach pains or cramps were rated on a 4-point Likert scale (none; mild; moderate; severe).

Volunteers came to the Department of Human Nutrition twice at the end of each supplement period to defaecate. Within $15 \mathrm{~min}$ after defaecation the faeces were weighed and immediately deep-frozen on dry ice to stop fermentation, then stored at $-20^{\circ}$.

On the last day of each supplement period, end-expiratory breath samples were taken at the Department of Human Nutrition at $4 \mathrm{~h}$ intervals from 08.00 hours (fasted) until 20.00 hours and again at 08.00 hours (fasted) the next morning. Urine $(24 \mathrm{~h})$ was collected on the last $2 \mathrm{~d}$ of every supplement period and $5 \mathrm{ml}$ glacial acetic acid was added to all urine bottles before collection as a preserving agent.

\section{Analytical procedures}

The $24 \mathrm{~h}$ urine samples were pooled when both collections were complete. Li was measured as described previously (Leclercq et al. 1990) using an atomic absorption spectrophotometer (Type 2380, Perkin-Elmer, Norwalk, CT, USA). Calibration was done with a standard concentration of $100 \mu \mathrm{mol} / 1$ and with water as a blank.

End-expiratory breath samples and ambient air samples were collected in plastic $60 \mathrm{ml}$ syringes (Plastipak; Becton Dickinson, Dublin, Ireland). $\mathrm{CH}_{4}$ was measured in endexpiratory breath samples, using GC (Chrompack 438 AS; Hewlett Packard 427, Middelburg, The Netherlands). Calibration was done (daily) with $5 \mathrm{ppm}$ and $29 \mathrm{ppm} \mathrm{CH}_{4}{ }^{-}$ in- $\mathrm{N}_{2}$ gases (Intermar b.v., Breda, The Netherlands). Within $2 \mathrm{~h}$ after collection the $\mathbf{H}_{2}$ concentration was measured using a standard electrochemical cell (exhaled hydrogen 
monitor; Gas Measurement Instruments Ltd, Renfrew, Scotland). The cell was calibrated with a standard gas of $100 \mathrm{ppm}_{2}$ in air (Intermar b.v.).

All faecal samples were X-rayed before analysis to determine the number of $\mathrm{Ba}$ rings (Philips Optimus M200, Eindhoven, The Netherlands). Dry weight of the faeces was estimated by drying a portion for $4 \mathrm{~d}$ at $80^{\circ}$ (Heraeus E45, Hanau, Germany).

For the preparation of the aqueous fraction of stool the samples were thawed overnight at $4^{\circ}$. The two samples from each week were homogenized in a bowl and mixer. A portion was ultracentrifuged at $26000 \mathrm{~g}$ for $90 \mathrm{~min}$ at $4^{\circ}$ (MSE, Scientific Instruments, Crawley, Sussex). Faecal water was carefully removed and stored at $-20^{\circ}$ until analysis. The $\mathrm{pH}$ was measured in both faecal homogenate and faecal water with a digital pH meter (CD 620; WPA Ltd, Cambridge, Cambs.)

Short-chain fatty acids were measured in faecal water as described by van Munster et al. (1994), using a Packard gas chromatograph (column: $10 \% \mathrm{SP} 1200 / 1 \% \mathrm{H}_{3} \mathrm{PO}_{4}$ on $80 / 100$ Chromosorb WAW, Hewlett Packard). The fructo-oligosaccharides present in faeces were determined in $0.25 \mathrm{~g}$ freeze-dried faeces. This was suspended in $5 \mathrm{ml}$ water, vortex-mixed and boiled for $10 \mathrm{~min}$. The suspension was centrifuged at $4500 \mathrm{rev}$. $/ \mathrm{min}$ for $25 \mathrm{~min}$. The supernatant fraction was analysed by high-performance anion-exchange chromatography (Dionex b.v., Breda, The Netherlands). The system consisted of a gradient pump and programmable pulsed electrochemical detector. Separations were performed using a Carbopack PA-100 analytical column $(4 \times 250 \mathrm{~mm}$, Dionex $)$. The chromatographic mobile phase consisted of $0.1 \mathrm{M}-\mathrm{NaOH}$ (A) and $1 \mathrm{~m}-\mathrm{Na}$-acetate containing $0.1 \mathrm{M}-\mathrm{NaOH}$ (B). A linear gradient was used from $100 \% \mathrm{~A}$ to $70 \% \mathrm{~A}$ plus $30 \% \mathrm{~B}$ in $25 \mathrm{~min}$ with a flow of $1 \mathrm{ml} / \mathrm{min}$. Samples were compared with spiked samples, containing three oligomers from Raftilose P95 (GF2, GF3 and GF4). The same HPLC method was used on undiluted urine samples for the detection of fructo-oligosaccharides in urine.

\section{Data analysis and statistics}

The $24 \mathrm{~h}$ integrated breath- $\mathrm{H}_{2}$ excretion was estimated by calculating geometrically the area under the curve of concentration $v$. time (Wolever \& Jenkins, 1986).

Results are expressed as means and standard errors, unless stated otherwise. The distributions of the differences between the three treatments were checked for normality by visual inspection of the normal probability plots. The significance of the differences between the three supplements in each subject was assessed by ANOVA without interactions (general linear models procedure). Because of a small number of missing values in the data set, leading to non-orthogonality of the model, the variable 'period' was added to the model. 'Period' did not contribute to the significance of the model, nor did it change any of the conclusions. Therefore the model used in the final analysis contained only 'subject' and 'treatment'. In cases of a significant difference $(P<0.05)$ between treatments, group means were tested with the Tukey or Scheffé tests.

An exception to the given method of analysis was made for the breath $\mathrm{H}_{2}$ data. Because of excessive numbers of missing values we used the least-square means statement to estimate mean values for each supplement and to evaluate differences between treatments in a model including 'subject', 'period' and 'treatment'. This analysis accounts for unequal cell sizes; least-square means are estimators of the marginal means that would be expected had the design been balanced.

The statistical analysis package SAS, version 6.09 (Statistical Analysis Systems Institute, Inc., Cary, NC, USA) was used to perform the statistical analyses. 


\section{RESULTS}

\section{Supplements and food intake}

None of the volunteers experienced great difficulties with the consumption of the supplements. All volunteers completed the study successfully. The recovery of $\mathrm{Li}$ in urine was significantly lower $(P<0.05)$ after consumption of SF15 $(82 \%)$ than after consumption of control $(90 \%)$. The results of the $2 \mathrm{~d}$ food records obtained during each supplement period revealed no changes in the average daily intakes of energy, protein, fat, carbohydrates or dietary fibre. Mean values of dietary intakes from $6 \mathrm{~d}$ food records are given in Table 1.

\section{Diaries}

The information from the diaries is presented in Table 2. Gastrointestinal complaints concerning flatulence were significantly higher $(P<0.001)$ during consumption of SF15 compared with the control supplement. Although flatulence did not rise significantly during SF5, there was a visible trend towards a higher level. All other symptom scores were low and equal for the three supplements.

There were no differences in recorded stool form between control and SF5. During SF15, stool form was rated somewhat lower and was more watery. This decrease, however, was not significant. No differences were found in frequency of defaecation between the supplements.

\section{Colonic fermentation}

Because of a technical defect of the exhaled $\mathrm{H}_{2}$ monitor in the last week of the experiment, we only obtained sixteen observations of $\mathrm{H}_{2}$ excretion (instead of twenty-four) in each supplement group. Fig. 1 shows the mean breath $\mathrm{H}_{2}$ curve for each supplementation. When comparing the separate $\mathrm{H}_{2}$ levels at different times we observed a significantly higher response $(P<0.01)$ at 12.00 hours for SF15.

Table 3 summarizes the fermentation data. When expressing the $\mathrm{H}_{2}$ excretion as the area under the $\mathrm{H}_{2}$-time curve (AUC) there was an increase in AUC from control (682 ppm.h) to SF5 (714 ppm.h; $P=0.78$, compared with control) and to SF15 (986 ppm.h; $P<0.05$ compared with control).

No changes in faecal weight were observed. The observed difference in wet weight between control and SF15 (or SF5) did not vary in any systematic way over the range of measurements. There was no significant correlation between differences in wet weight in response to supplementation and average values of wet weight (for SF5: $r-0.03 ; P=0.89$, for SF15: $r-0.26 ; P=0.26$ ). Four observations were excluded from the analysis of wet weight because volunteers had forgotten to swallow all $\mathrm{Ba}$ rings in that week, making it impossible to estimate daily productions.

Faecal dry weight, expressed as a percentage of wet weight, did not change in response to the supplementation. No traces of the fructo-oligosaccharides that were provided in the supplement were recovered in any of the faecal samples. Figure 2 gives an example of a typical HPLC elution pattern for a faecal sample from one of the volunteers during SF15. Response $\mathrm{A}$ is Raftilose P95, response $\mathrm{B}$ is the sample spiked with the Raftilose P95 oligomers GF2, GF3 and GF4, response $C$ is the unspiked sample.

In addition to faecal analyses, we also analysed urine samples for fructo-oligosaccharides. In none of the samples were any fructo-oligosaccharides detected.

Concentrations of short-chain fatty acids were measured in faecal water. No accumulation of these fermentation products was observed. As shown in Fig. 3, the relative contributions of different short-chain fatty acids did not change. The $\mathrm{pH}$ values of faecal water and homogenate were not altered in response to the different supplements. Because 
Table 2. Effect of dietary supplementation with 0 (control), 5 (SF5) or 15 (SF15) g fructooligosaccharides/d on gastrointestinal complaints, stool form and frequency of defaecation $\dagger$

(Mean values with their standard errors for twenty-four subjects)

\begin{tabular}{|c|c|c|c|c|c|c|c|c|c|c|}
\hline & \multicolumn{2}{|c|}{ Flatulence $\$$} & \multicolumn{2}{|c|}{ Bloating } & \multicolumn{2}{|c|}{$\begin{array}{l}\text { Abdominal pains } \\
\text { or cramps } f\end{array}$} & \multicolumn{2}{|c|}{ Stool form§ } & \multicolumn{2}{|c|}{$\begin{array}{l}\text { Frequency of } \\
\text { defaecationil }\end{array}$} \\
\hline & Mean & $\mathrm{SE}$ & Mean & $\mathrm{SE}$ & Mean & SE & Mean & $\mathrm{SE}$ & Mean & $\mathbf{S E}$ \\
\hline \multicolumn{11}{|l|}{ Supplement: } \\
\hline Control & 0.5 & $0 \cdot 1$ & $0 \cdot 1$ & $0 \cdot 1$ & 0.0 & $0 \cdot 0$ & $3 \cdot 3$ & $0 \cdot 1$ & $1 \cdot 2$ & $0-1$ \\
\hline SF5 & 0.7 & $0 \cdot 1$ & $0 \cdot 1$ & $0 \cdot 1$ & $0 \cdot 0$ & $0 \cdot 0$ & $3 \cdot 2$ & $0 \cdot 2$ & $1 \cdot 3$ & $0 \cdot 1$ \\
\hline SF15 & $1 \cdot 0^{* * *}$ & $0 \cdot 1$ & $0 \cdot 2$ & $0 \cdot 1$ & $0 \cdot 1$ & 0.0 & $3 \cdot 1$ & $0 \cdot 1$ & $1 \cdot 2$ & $0 \cdot 1$ \\
\hline \multicolumn{11}{|c|}{ Analysis of variance: } \\
\hline df MSE & \multicolumn{2}{|l|}{46} & \multicolumn{2}{|c|}{46} & \multicolumn{2}{|c|}{46} & \multicolumn{2}{|c|}{46} & \multicolumn{2}{|c|}{46} \\
\hline Supplement & \multicolumn{2}{|c|}{$P<0.001$} & \multicolumn{2}{|c|}{ NS } & \multicolumn{2}{|c|}{ NS } & \multirow{2}{*}{\multicolumn{2}{|c|}{$\begin{array}{c}\text { NS } \\
P<0.0001\end{array}$}} & \multirow{2}{*}{\multicolumn{2}{|c|}{$\begin{array}{c}\text { NS } \\
P<0.0001\end{array}$}} \\
\hline Subject & \multicolumn{2}{|c|}{$P<0.0001$} & \multicolumn{2}{|c|}{$P<0.0001$} & \multicolumn{2}{|c|}{ NS } & & & & \\
\hline Differences: & & & & & & & \multicolumn{2}{|c|}{$P<0.0001$} & \multicolumn{2}{|c|}{$2-0,000$} \\
\hline SF5-control & 0.2 & $0 \cdot 1$ & 0.0 & 0.0 & -0.0 & 0.0 & -0.0 & $0 \cdot 1$ & $0 \cdot 1$ & $0 \cdot 1$ \\
\hline SF15-control & 0.4 & 0.1 & 0.1 & 0.0 & $0 \cdot 1$ & 0.0 & -0.1 & 0.1 & 0.1 & $0 \cdot 1$ \\
\hline
\end{tabular}

df, Degrees of freedom; MSE, mean square error.

*** Mean value was significantly different from control, $P<0.001$.

+ For details of subjects and procedures, see Table 1 and pp. 212-214.

$\$$ Subjects scored symptoms on a scale from 0 (none) to 3 (severe). Symptom scores for eructations, nausea, vomiting and stomach pains or cramps were zero for all supplements.

$\S$ Stool form was rated on a scale from 1 (watery) to 5 (dry, hard pellets).

II Mean frequency per day in each supplement week.

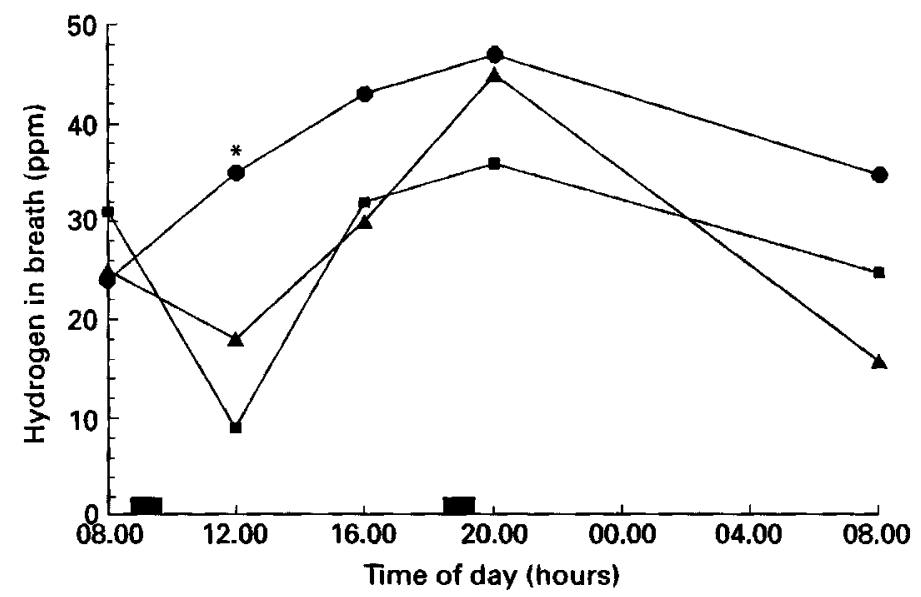

Fig. 1. Least-square means (LS Means) of breath hydrogen concentrations (ppm) at regular time intervals on the seventh day of supplementation with $0(\boldsymbol{D}), 5(\mathbf{A})$ or $15 \mathrm{~g}(\mathbf{O})$ fructo-oligosaccharides. LS Means are based on sixteen observations for each plotted point. ( Time of supplement ingestion. ${ }^{*} P<0.01$ in comparison with control.

there were three cases in which the amount of extractable faecal water was negligible, faecal short-chain fatty acids and $\mathrm{pH}$ of faecal water could not be measured for these observations. There was a significant negative correlation between the $\mathrm{pH}$ of faecal water and the total amount of short-chain fatty acids $(r-0.57, P<0.0001)$ as measured in faecal water. 
Table 3. Effect of dietary supplementation with 0 (control), 5 (SF5) or 15 (SF15) g fructooligosaccharides/d on breath hydrogen excretion, faecal weight, faecal $p H$ and short-chain fatty acid concentrations $\dagger$

(Mean values with their standard errors for twenty-four subjects)

\begin{tabular}{|c|c|c|c|c|c|c|c|c|c|c|}
\hline & \multicolumn{2}{|c|}{$\begin{array}{l}\text { Breath hydrogen } \\
\text { (ppm.h) } \ddagger\end{array}$} & \multicolumn{2}{|c|}{$\begin{array}{l}\text { Faecal wet wt } \\
(\mathrm{g} / \mathrm{d}) \S\end{array}$} & \multicolumn{2}{|c|}{$\begin{array}{l}\text { Faecal dry wt } \\
\text { (g/kg wet wt) }\end{array}$} & \multicolumn{2}{|c|}{ Faecal pH\| } & \multicolumn{2}{|c|}{$\begin{array}{l}\text { Short-chain } \\
\text { fatty acids } \\
\text { (mmol/l) }\end{array}$} \\
\hline & Mean & SE & Mean & SE & Mean & SE & Mean & SE & Mean & $\mathbf{S E}$ \\
\hline \multicolumn{11}{|l|}{ Supplement: } \\
\hline Control & 682 & 80 & 272 & 26 & 245 & 9 & 6.5 & $0 \cdot 1$ & 151 & 7 \\
\hline SF5 & 714 & 77 & 279 & 33 & 232 & 12 & $6 \cdot 4$ & 0.1 & 150 & 7 \\
\hline SF 15 & $986^{*}$ & 85 & 264 & 22 & 237 & 7 & 6.4 & 0.1 & 153 & 8 \\
\hline \multicolumn{11}{|c|}{ Analysis of variance: } \\
\hline df MSE & \multirow{2}{*}{\multicolumn{2}{|c|}{$\begin{array}{c}19 \\
\text { NS }\end{array}$}} & \multirow{2}{*}{\multicolumn{2}{|c|}{39}} & \multirow{2}{*}{\multicolumn{2}{|c|}{46}} & \multirow{2}{*}{\multicolumn{2}{|c|}{45}} & \multicolumn{2}{|c|}{43} \\
\hline Period & & & & & & & & & & \\
\hline Supplement & \multirow{2}{*}{\multicolumn{2}{|c|}{$\begin{array}{l}P<0.05 \\
P<0.01\end{array}$}} & \multirow{2}{*}{\multicolumn{2}{|c|}{$\begin{array}{c}\text { NS } \\
P<0.0001\end{array}$}} & \multirow{2}{*}{\multicolumn{2}{|c|}{$\begin{array}{c}\text { NS } \\
P<0.0001\end{array}$}} & \multirow{2}{*}{\multicolumn{2}{|c|}{$\begin{array}{c}\text { NS } \\
P<0.0001\end{array}$}} & \multirow{2}{*}{\multicolumn{2}{|c|}{$\begin{array}{c}\text { NS } \\
P<0.01\end{array}$}} \\
\hline Subject & & & & & & & & & & \\
\hline \multicolumn{11}{|l|}{ Differences: } \\
\hline SF5-control & 32 & 116 & -32 & 20 & -13 & 9 & -0.1 & $0 \cdot 1$ & -4 & 9 \\
\hline SF15-control & 304 & 120 & -17 & 25 & -8 & 8 & 0 & 0.1 & 3 & 7 \\
\hline
\end{tabular}

df, Degrees of freedom; MSE, mean square error.

* Mean value was significantly different from control, $P<0.05$.

$\uparrow$ For details of subjects and procedures, see Table 1 and pp. 212-214.

Least-square means (LS Means) and standard errors of the LS Means; $n 16$ for each supplement group.

$\S$ Mean daily production as estimated from marker recovery. Four observations were excluded because markers were not swallowed.

$\|$ As measured in faecal water. Three observations were missing because there was too little faecal water extractable from faeces.

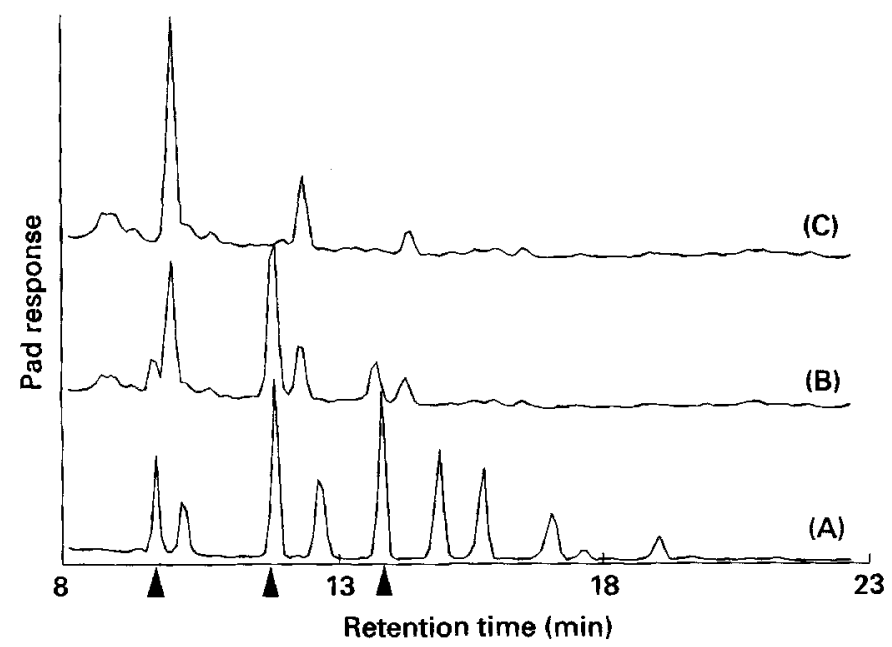

Fig. 2. Typical HPLC patterns for one of the volunteers. Samples were (A) Raftilose P95, (B) faecal sample after supplementation with fructo-oligosaccharides, spiked with three oligomers from Raftilose P95 ( $\mathbf{\Lambda}$ ), (C) the same faecal sample, unspiked. 


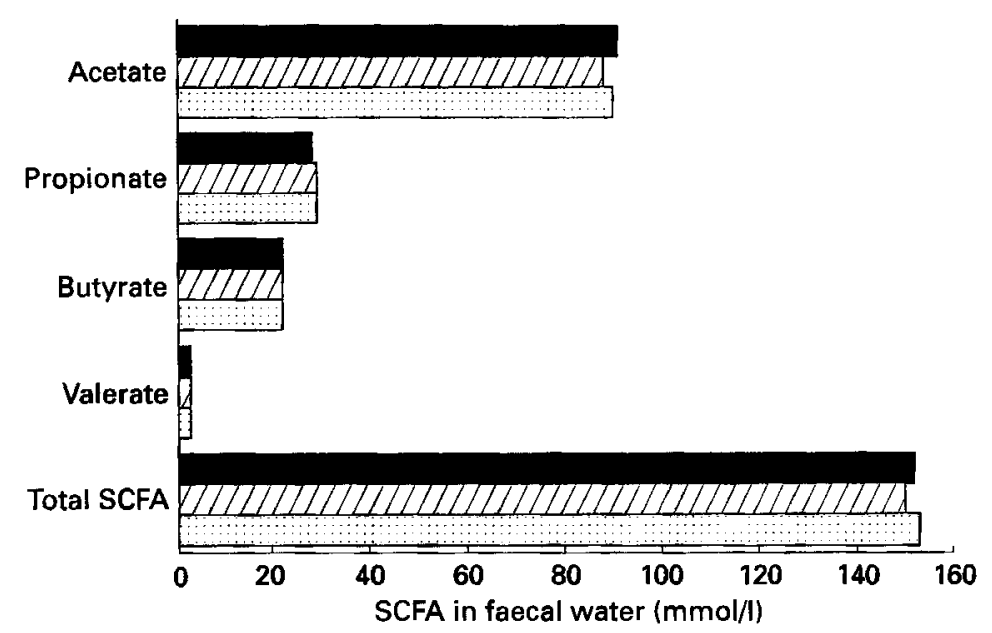

Fig. 3. Mean concentration of short-chain fatty acids (SCFA) as measured in faecal water obtained from two pooled stools, after 5-7 d of dietary supplementation with $0(\square), 5(\square)$ or $15 \mathrm{~g}(\mathrm{Q})$ fructo-oligosaccharides.

\section{DISCUSSION}

This study shows that fructo-oligosaccharides are completely fermented in the large intestine.

Complete malabsorption in the small intestine was confirmed, since no fructooligosaccharides were detected in any of the urine samples, and it has been shown that fructo-oligosaccharides are not metabolized by human digestive enzymes in the small intestine (Oku et al. 1984; Nilsson \& Björck, 1988; Tokunaga et al. 1989) and thus reach the large intestine. We demonstrated fermentation positively through the observed increase of breath $\mathrm{H}_{2}$ excretion. This fermentation was complete, since no fructo-oligosaccharides were excreted in faeces during the last $2 \mathrm{~d}$ of each supplementation period. The present study is the first to show the complete fermentation of fructo-oligosaccharides in an in vivo experiment.

The increase of $\mathrm{H}_{2}$ excretion during fermentation of fructo-oligosaccharides has also been observed by other investigators (Stone-Dorshow \& Levitt, 1987; Rumessen et al. $1990 \mathrm{a}$; Gibson et al. 1995). The level of breath $\mathrm{H}_{2}$ excretion seems to be dose-dependent. During SF5 the excretion was higher than during the control period, although it did not reach significance. At the SF15 level the excretion of $\mathrm{H}_{2}$ was significantly higher than during the control treatment. This dose effect was also observed by Rumessen et al. (1990 a) using fructans, which are longer-chain oligomers. It is unlikely that the effect on $\mathrm{H}_{2}$ excretion during SF5 was missed because of a rapid fermentation and short-lived increases of breath $\mathrm{H}_{2}$. The $\mathrm{H}_{2}$ response to fructo-oligosaccharides might be rapid, but the concentration is shown to be elevated for at least $6 \mathrm{~h}$ after supplementation (StoneDorshow \& Levitt, 1987). A more likely explanation for the very small difference between control and SF5 is that the effect was masked by the meal-related $\mathrm{H}_{2}$ response.

In the present study it was impossible to test for linearity, since we only tested three doses of fructo-oligosaccharides. However, in a study by Rumessen et al. (1990 b) the excretion of $\mathrm{H}_{2}$ in breath increased linearly with the consumption of up to $20 \mathrm{~g}$ lactulose.

We did not find any increase in short-chain fatty acid concentration in faeces after supplementation with fructo-oligosaccharides and, consequently, no changes in the average $\mathrm{pH}$ values of faecal water. Short-chain fatty acids are mainly produced in the proximal colon where the amount of available substrates is highest (Macfarlane et al. 1992). Rapid 
absorption by the colonic mucosa leads to a lower concentration in the faeces (Höverstad et al. 1982; Cummings et al. 1987). This is probably the reason that we did not find the expected changes in short-chain fatty acids or $\mathrm{pH}$.

Our results were in accordance with the recent findings of Gibson et al. (1995) who published a study investigating the effects of fructo-oligosaccharides on large-bowel microflora and colonic function in a controlled feeding trial $(n 8)$. They did not observe any major differences in faecal short-chain fatty acid concentration between supplementation with $15 \mathrm{~g}$ fructo-oligosaccharides or sucrose. In an experiment by Mitsuoka et al. (1987) the effects of fructo-oligosaccharides on intestinal microflora and faecal $\mathrm{pH}$ were evaluated. Elderly patients ( $n$ 23) participated in a 3 -week experiment. They consumed $8 \mathrm{~g}$ fructooligosaccharides/d for 2 weeks. Faecal collection took place before, during and after administration. A mean decrease of faecal $\mathrm{pH}$ (by 0.3 units) was observed, but no information was given on variations or levels of significance. No control treatment was used.

In the present study, supplementation with fructo-oligosaccharides, even at the SF15 level, did not cause changes in stool form, wet or dry weight of faeces or frequency of defaecation. Our findings on faecal mass were surprising. We expected that increased fermentation would lead to an increase of total microbial mass. As this microbial mass is estimated to be about $55 \%$ of the total faecal solids, a faecal weight change was anticipated (Stephen \& Cummings, 1980), Ito et al. (1990) investigated the effects of administering galacto-oligosaccharides on different variables. No changes in faecal weight were observed after testing different doses of galacto-oligosaccharides using a strict study design. Gibson et al. (1995) showed a trend towards higher faecal wet and dry weights. Since the excretion of $\mathrm{N}$ was significantly higher during supplementation with fructo-oligosaccharides, the authors concluded that the increase in faecal weight was probably due to an increase in biomass. Little effect was shown on total bacterial counts per gram faeces. The present study was performed under uncontrolled dietary conditions and therefore correction for dietary fibre intake was impossible. The bulking capacity of dietary fibre might have influenced the faecal weights in this study (Cummings et al. 1992) and possibly masked the effect of biomass on faecal weight. Moreover, it should be noted that fibre intakes were relatively high compared with the average intake by Dutch men of the same age category $(40 \mathrm{~g} / \mathrm{d}$ v. $27 \mathrm{~g} / \mathrm{d})$ (Ministerie van Welzijn \& Ministerie van Landbouw en Visserij, 1988). This is also reflected in the daily stool output (mean $270 \mathrm{~g} / \mathrm{d}$ ) which is considerably higher than reported values for healthy male adults in the UK (mean $122 \mathrm{~g} / \mathrm{d}$; Cummings et al. 1992).

In general, the volunteers accepted the sweet taste of fructo-oligosaccharides well. The only negative remark concerned the increase in flatulence during SF15 supplements.

The fructo-oligosaccharide supplements were marked with $\mathrm{Li}$ in order to check compliance of intakes. Li recovery was $82 \%$ during SF15, which was significantly lower than the $90 \%$ recovery during control. If this was due to a lower intake of SF 15 then the intake of fructo-oligosaccharides at this level might not have been $15 \mathrm{~g}$, but between 13.5 and $14 \mathrm{~g} / \mathrm{d}$. This would still have been high compared with the estimated daily consumption of fructo-oligosaccharides, which is only about $1 \mathrm{~g} / \mathrm{d}$ (Spiegel et al. 1994).

We conclude that fructo-oligosaccharides added to the diet of young Western subjects are fully metabolized in the large intestine. The next step is to study in depth the specific effects of supplementation with fructo-oligosaccharides on microfloral growth and metabolism. Gibson et al. (1995) recently reported interesting results suggesting that supplementation with oligosaccharides might lead to the establishment of a more healthy colonic community, through the selective stimulation of bifidobacteria. 
We are indebted to the volunteers for their cooperation. We thank Susanne Hovens, Mariska Hospers and Chantal Hukkelhoven for their help in conducting the experiment. We also thank Meijke Booy, Jan Burema, Frans Schouten and Albert Tangerman for helping with the analyses. The authors gratefully acknowledge the financial support for this study, which is part of a multi-donor-funded research programme on the role of nondigestible oligosaccharides in food and feed.

\section{REFERENCES}

Cummings, J. H., Bingham, S. A., Heaton, K. W. \& Eastwood, M. A. (1992). Fecal weight, colon cancer risk, and dietary intake of nonstarch polysaccharides (dietary fibre). Gastroenterology 103, 1783-1789.

Cummings, J. H., Pomare, E. W., Branch, W. J., Naylor, C. P. E. \& Macfarlane, G. T. (1987). Short-chain fatty acids in human large intestine, portal, hepatic and venous blood. Gut 28, 1221-1227.

Gibson, G. R., Beatty, E. R., Wang, Z. \& Cummings, J. H. (1995). Selective stimulation of bifidobacteria in the human colon by oligofructose and inulin. Gastroenterology 108, 975-982.

Hayakawa, K., Mizutani, J, Wada, K., Masai, T., Yoshihara, I. \& Mitsuoka, T. (1990). Effects of soybean oligosaccharides on human faecal flora. Microbial Ecology in Health and Disease 3, 293-303.

Heaton, K. W., Radvan, J., Cripps, H., Mountford, R. A., Braddon, F. E. M. \& Hughes, A. O. (1992). Defecation frequency and timing, and stool form in the general population: a prospective study. Gut 33, 818-824.

Hidaka, H., Eida, T., Takizawa, T., Tokunaga, T. \& Tashiro, Y. (1986). Effects of fructooligosaccharides on intestinal flora and human health. Bifidobacteria Microflora 5, 37-50.

Höverstad, T., Böhmer, T. \& Fausa, O. (1982). Absorption of short chain fatty acids from the human colon measured by the ${ }^{14} \mathrm{CO}_{2}$ breath test. Scandinavian Journal of Gastroenterology 17, 373-378.

Ito, M., Deguchi, Y., Miyamori, A., Matsumoto, K., Kikuchi, H., Kobayashi, Y., Tajema, Y. \& Kan, T. (1990). Effects of administration of galactooligosaccharides on the human faecal microflora, stool weight and abdominal sensation. Microbial Ecology in Health and Disease 3, 285-292.

Koo, M. \& Rao, A. V. (1991). Long-term effect of Bifidobacteria and Neosugar on precursor lesions of colonic cancer in CF1 mice. Nutrition and Cancer 16, 249-257.

Leclercq, C., Avalle, V., Ranaldi, L., Toti, E. \& Ferro-Luzzi, A. (1990). Simplifying the lithium-marker technique used to assess the dietary intake of discretionary sodium in population studies. Clinical Science 79, 227-231.

McBurney, M. I. (1991). Starch malabsorption and stool excretion are influenced by the menstrual cycle in women consuming low-fibre western diets. Scandinavian Journal of Gastroenterology 26, 880-886.

Macfarlane, G. T., Gibson, G. R. \& Cummings, J. H. (1992) Comparison of fermentation reactions in different regions of the human colon. Journal of Applied Bacteriology 72, 57-64.

Masai, T., Wada, K., Hayakawa, K., Yoshihara, I. \& Mitsuoka, T. (1987). Effects of soybean oligosaccharides on human intestinal flora and metabolic activities. Japanese Journal of Bacteriology 42, 313-325.

Ministerie van Welzijn, Volksgezondheid en Cultuur \& Ministerie van Landbouw en Visserij (1988). Wat eet Nederland: resultaten van de voedselconsumptiepeiling 1987-1988. Rijswijk: Centrale Directie Voorlichting, Documentatie en Bibliotheek.

Mitsuoka, T. (1990). Bifidobacteria and their role in human health. Journal of Industrial Microbiology 6, 263-268.

Mitsuoka, T., Hidaka, H. \& Eida, T. (1987). Effect of fructo-oligosaccharides on intestinal microflora. Die Nahrung 31, 427-436.

Modler, H. W., McKellar, R. C. \& Yaguchi, M. (1990). Bifidobacteria and bifidogenic factors. Canadian Institute of Food Science and Technology 23, 29-41.

Nagengast, F. M., van Erp, J., Koopman, J. \& van Tongeren, J. (1988). The relationship between methane $\left(\mathrm{CH}_{4}\right)$ production in vitro and excretion in breath. Gastroenterology 94, A319.

Nilsson, U. \& Björck, I. (1988). Availability of cereal fructans and inulin in the rat intestinal tract. Journal of Nutrition 118, 1482-1486.

Oku, T., Tokunaga, T. \& Hosoya, N. (1984). Nondigestibility of a new sweetener, 'Neosugar', in the rat. Journal of Nutrition 114, 1574-1581.

Rumessen, J. J. (1992). Hydrogen and methane breath tests for evaluation of resistant carbohydrates. European Journal of Clinical Nutrition 46, S77-S90.

Rumessen, J. J., Bodé, S., Hamberg, O. \& Gudmand-Hoyer, E. (1990a). Fructans of Jerusalem artichokes: intestinal transport, absorption, fermentation, and influence on blood glucose, insulin, and C-peptide responses in healthy subjects. American Journal of Clinical Nutrition 52, 675-681.

Rumessen, J. J., Hamberg, O. \& Gudmand-Hoyer, E. (1990 b). Interval sampling of end-expiratory hydrogen concentrations to quantify carbohydrate malabsorption. Gut 31, 37-42.

Sanchez-Castillo, C. P., Seidell, J. \& James, W. P. T. (1987). The potential use of lithium as a marker for the assessment of the sources of dietary salt: cooking studies and physiological experiments in men. Clinical Science 72, 81-86.

Spiegel, J. E., Rose, R., Karabell, P., Frankos, V. H. \& Schmitt, D. F. (1994). Safety and benefits of fructooligosaccharides as food ingredients. Food Technology January, 85-89. 
Stephen, A. M. \& Cummings, J. H. (1980). The microbial contribution to human faecal mass. Journal of Medical Microbiology 1345, 45-56.

Stichting Nederlands Voedingsstoffenbestand (NEVO) (1986). NEVO Table (in Dutch), The Hague: The Netherlands Bureau for Food and Nutrition Education.

Stone-Dorshow, T. \& Levitt, M. D. (1987). Gaseous response to ingestion of a poorly absorbed fructooligosaccharide sweetener. American Journal of Clinical Nutrition 46, 61-65.

Tokunaga, T., Oku, T. \& Hosoya, N. (1989). Utilization and excretion of a new sweetener, fructooligosaccharide (neosugar), in rats. Journal of Nutrition 119, 553-559.

van Houwelingen, R., Nordoy, A., van der Beek, E., Houtsmuller, U., de Metz, M. \& Hornstra, G. (1987). Effect of a moderate fish intake on blood pressure, bleeding time, hematology, and clinical chemistry in healthy males. American Journal of Clinical Nutrition 46, 424-436.

van Munster, I. P., Tangerman, A. \& Nagengast, F. M. (1994). Effect of resistant starch on colonic fermentation, bile acid metabolism, and mucosal proliferation. Digestive Diseases and Sciences 39, 834-842.

Wang, X. \& Gibson, G. R. (1993). Effects of the in vitro fermentation of oligofructose and inulin by bacteria growing in the human large intestine. Journal of Applied Bacteriology 75, 373-380.

Wolever, T. M. S. \& Jenkins, D. J.A. (1986). The use of the glycemic index in predicting the blood glucose response to mixed meals. American Journal of Clinical Nutrition 43, 167-172. 